\title{
Trends in the genesis and landfall locations of tropical cyclones over the Bay of Bengal in the current global warming era
}

\author{
Dodla Venkata Bhaskar Rao ${ }^{1}$, Desamsetti Srinivas ${ }^{1, *}$ \\ and Gubbala China Satyanarayana ${ }^{2}$ \\ ${ }^{1}$ Department of Meteorology and Oceanography, Andhra University, Visakhapatnam, Andhra Pradesh 530003, \\ India. \\ ${ }^{2}$ Department of Atmospheric Science, K L University, Green Fields, Vaddeswaram, Andhra Pradesh 522 502, India. \\ ${ }^{*}$ Corresponding author. e-mail: sreeds82@gmail.com
}

MS received 19 September 2018; revised 9 May 2019; accepted 13 May 2019; published online 5 July 2019

Trends in tropical cyclone (TC) genesis and landfall over the Bay of Bengal (BOB) were analysed to identify global warming and climate change impacts. The historical TC data for the period 1901-2015 available through the cyclone eAtlas from India Meteorological Department were used. The analysis was confined to the 3-month period from October to December when the maximum number of TCs occurs over the BOB. Analysis was conducted for the two 50-yr periods of 1901-1950 and 1961-2010 and the four 30-yr periods of 1921-1950, 1961-1990, 1971-2000 and 1981-2010 to ascertain the differences and tendencies in the genesis and landfall points during the current global warming era since the 1960s and the previous years. The results indicate an increase of TC genesis over the south-east and central BOB and decrease over the south central region. Furthermore, an increased vulnerability of the Bangladesh coastline to TC landfall was detected. In addition, TC systems had decreased in number but increased in intensity. These results confirm the general reports of TC trends over the BOB as of other ocean basins in the post-industrialisation global warming era.

Keywords. Tropical cyclones; climate change; global warming; genesis; landfall.

\section{Introduction}

Tropical cyclones (TCs) are known to be the most devastating of all natural disasters due to their impact as the loss of human lives and large-scale economic losses over a wide area (Diaz and Pulwarty 1997). Vulnerability to TCs is noted to be continuously escalating because of the growing habitation and increasing critical infrastructure along the tropical coastal regions. The vulnerability of the loss of human lives is higher in underdeveloped countries, whereas the economic impacts are the same for all regions. For this reason, the assessment of global warming and climate change impacts on TCs over different ocean basins gained practical importance. According to the Fifth Assessment report of the Intergovernmental Panel on Climate Change (IPCC) (IPCC 2013), "the characteristics of extreme weather and climate events are changing, risk and exposure continue to increase and preparation and adaptation are essential'. Assessment of future changes in frequency and intensity of TCs due to global warming is subject to uncertainty arising out of the 
predictions themselves. Although scientific understanding of the formation, intensification and movement continues to improve, gaps in the historical records of TCs puts a constraint on the linking of TC metrics to climate change. As a result, the observed trends are viewed with low confidence due to the attribution of these trends to human influences.

TC is the generic term for a non-frontal synoptic-scale, low pressure system originating over the tropical or subtropical waters with organised convection and definite cyclonic surface wind circulation. According to the nomenclature of the India Meteorological Department (IMD), TCs are referred to with different names depending on the maximum sustained surface winds, as a 'low pressure system' when wind speeds are less than 17 knots, 'depression' when they range from 17 to 27 knots, 'deep depression' when wind speeds are 28-33 knots, 'cyclonic storm' when the wind speeds are 34-47 knots, 'severe cyclonic storm' when wind speeds range from 48 to 63 knots, 'very severe cyclonic storm' when wind speeds range from 64 to 119 knots and 'super cyclonic storm' when wind speeds exceed 119 knots. Around the globe, about 80-90 systems attaining cyclonic storm intensity (34 knots) occur annually, of which about twothirds reach very severe cyclonic storm intensity (64 knots) (Sellers et al. 1998). In the North Indian Ocean (NIO), the annual average of cyclonic storms (CS) is only 5.2 which is $\sim 6 \%$ of the global frequency and this smaller frequency puts additional constraints to uncertainties in trend analysis. Most of the studies hitherto pertaining to the characteristics of TCs provided conflicting results, mainly because of large amplitude fluctuations in the frequency and intensity of TCs and lack of global historical records of TCs. Christensen et al. (2013), as a part of the IPCC report, stated that the global frequency of TCs will either decrease or remain essentially unchanged, an increase in mean TC maximum wind speed is likely, and that the frequency of the most intense storms will increase substantially in some ocean basins. Future projections based on high-resolution dynamical models consistently indicate that under global warming and climate change, the globally averaged intensity of TCs increases by $2-11 \%$ and globally averaged frequency of TCs decreases by 6-34\% (IPCC 2013).

The authors affirm that there could be inconsistencies in the data regarding the intensity reports of the past TCs in the NIO and also assume that the data archives of IMD had included records of all
TCs that have occurred over NIO discarding the possibility of the missing identities as the Bay of Bengal (BOB) and the Arabian Sea basins comprising NIO are small in size and frequented by ships. These premises form the basis of this study towards the identification of trends in the landfall and genesis locations over the BOB using IMD data. Furthermore, the analysis covers the 115-yr period of 1901-2015, of which the base period is taken as 1901-1950, and the representative period of global warming as from 1961 onwards, considering the scientific reports and results (Brohan et al. 2006; IPCC 2007; Rahmstorf et al. 2017). Details of the data set are given in section 2 . This study is confined to the BOB only as the cyclonic systems in the BOB are more than of the Arabian Sea and most of the coastlines of Bangladesh and Myanmar and the east coast of India are affected by TCs of the BOB (Bhaskar Rao et al. 2001). Furthermore, the analysis is restricted to the 3 -month period from October to December corresponding to the maximum frequency of TCs over the BOB. Analysis of TCs during the pre-monsoon months of March-April-May is not considered as their annual frequency is only 0.62 (total number is 72 during the study period of $115 \mathrm{yr}$ ), which is about $30 \%$ of the TCs in the post-monsoon season. This study was carried out in two parts, the first part dealing with the landfall and the second part with genesis. The methodology is presented in section 3. Statistical analyses were conducted to investigate the climate change impacts on the number of TCs and their landfalls during the pre- and current global warming era. The results are described in section 4 . Plausible interpretations of the identified climate change impacts are discussed in section 5 and summary and conclusions are given in section 6 .

\section{Data}

Data on the tracks of TCs and their genesis locations over the BOB for the period from 1901 to 2015 was retrieved from the 'cyclone eAtlas' as available from the IMD (http://www.rmcchennai eatlas.tn.nic.in/login.aspx?ReturnUrl $=\% 2 \mathrm{f} \quad$ View ByParam.aspx) for this study. IMD is the National Weather Service of India with a mandate for monitoring, tracking and forecasting the movement of cyclones and depressions of NIO. Regional Meteorological Centre, Chennai digitised the tracks of depressions and cyclones that occurred over the Indian seas and produced the eAtlas, an 
electronic version with software to generate related tracks, statistics in map, charts and tables. The details of the eAtlas are well documented (http:// www.rmcchennaieatlas.tn.nic.in/Documentation. aspx?doctype=Notes). All the cyclonic systems (total of CS and severe cyclonic storms (SCS)) that formed and attained the stage of TC (with maximum sustainable wind of $\geq 34$ knots) during the 3 -month period from October to December over the $\mathrm{BOB}$ region are considered for analysis. The track positions in the eAtlas are marked at 03 UTC i.e., 24-h interval based on data at a 3- or 6-h interval. The monthly means of low level $\mathrm{hPa}$ vorticity, lower tropospheric humidity, zonal wind at 850 and $200 \mathrm{hPa}$ levels were obtained from the European Centre for Medium-Range Weather Forecasts 20th century reanalysis project (ERA20C; Poli et al. 2016). The monthly means of sea surface temperature (SST) available at a two-degree horizontal resolution from the National Oceanic and Atmospheric Administration (NOAA) Extended Reconstructed SST (ERSST V.3; Smith and Reynolds 2003; Smith et al. 2008) for the period 1901-2010 were used in the present study.

\section{Methodology}

The study comprises two parts. The first part deals with the analysis of landfall locations. For this analysis, the coastlines of Myanmar and Bangladesh and the east coast of India have been divided into five regions specified as (i) $8-11.999 \mathrm{~N}$, 78-82E (R1); (ii) $12-15.999 \mathrm{~N}, 78-82 \mathrm{E}$ (R2); (iii) $16-19.999 \mathrm{~N}, \quad 80-87 \mathrm{E}$ (R3); (iv) $20-23.999 \mathrm{~N}$, 86-94E (R4) and (v) 16-19.999N, 92-96E (R5) (figure 1). The required information on the number of TCs having landfall in each of these five regions have been obtained from the eAtlas.

The second part of the study deals with the genesis of the TCs over the BOB. For the purpose of analysis, the BOB region lying between $5-20 \mathrm{~N}$ and $80-95 \mathrm{E}$ was divided into nine sub-regions, identified as genesis box regions (B1-B9) as shown in figure 2 and their regional extents are given in table 1 .

As per the statement given in section 1 stating the current global warming era to be from 1960 onwards, the analysis was made for the two 50-yr periods of 1901-1950 and 1961-2010 as representative of pre-warming and warming periods; and four 30-yr periods (30-yr period is taken to be representative of climate statistics). The first 30-yr

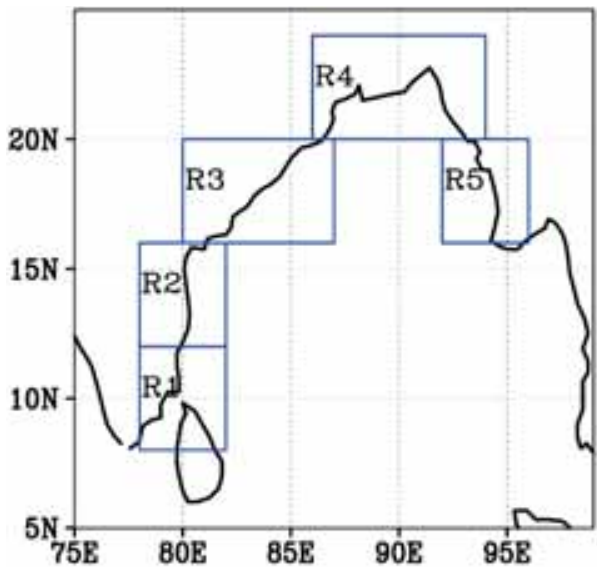

Fig. 1. Segregated regions of TC landfall covering the east coast of India and the coastal regions of Bangladesh and Myanmar.

period of 1921-1950 is considered as the base period representative of pre-warming, and the other three 30-yr periods of 1961-1990, 1971-2000 and 1981-2010 representative of the current warming era.

The numbers of genesis points lying in each of these regions were obtained from the eAtlas. The information thus obtained for the landfall points and genesis locations was analysed to identify trends reflecting climate-change impacts.

\section{Results}

\subsection{Trends in TC landfall}

As mentioned in section 1, landfall points of TCs during the period 1901-2015 have been analysed for the identification of trends in association with global warming and climate change. For this purpose, the number of TCs that had landfall in the specified five regions is identified during the total period 1901-2015; and the periods of 1901-1950, 1961-2010, 1921-1950, 1961-1990, 1971-2000 and 1981-2010 to ascertain the differences between the 50 -yr periods of the current global warming era and the previous era; one $30-y r$ period during the preglobal warming (1921-1950) period and three recent $30-y r$ periods in the global warming era. The numerics are presented in table 2. During the period 1901-2015, a total of 192 TCs had their landfall, of which 81 occurred during 1901-1950 and 94, during 1961-2010. Of the five regions, R4 is identified to be the most vulnerable with 63 TCs followed by R2, R3 and R1 and R5 had the least of TC landfall. 


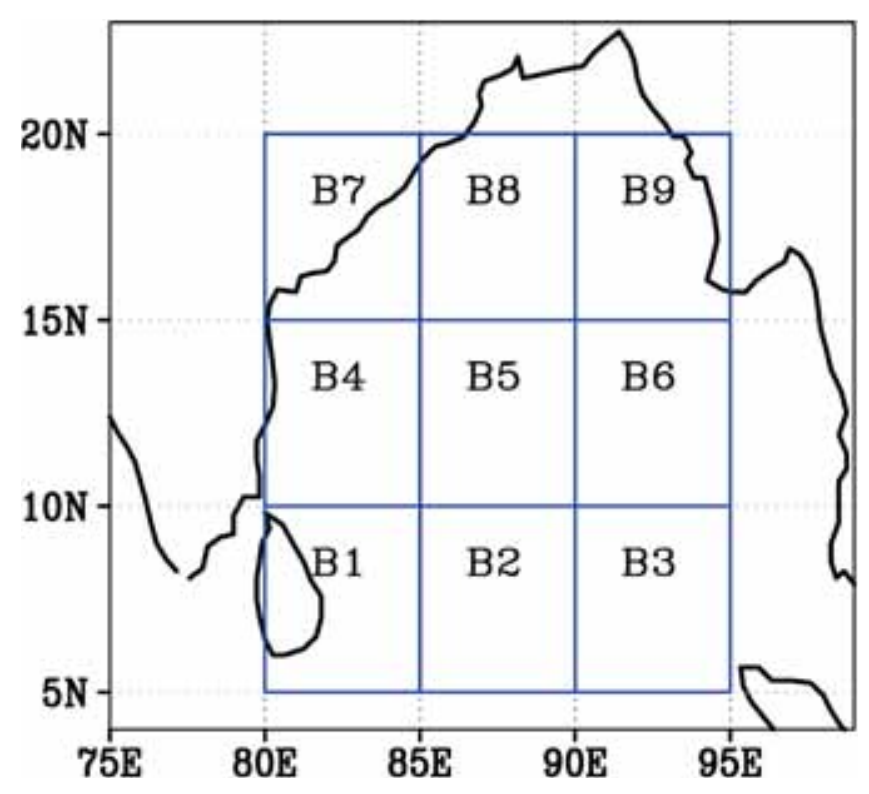

Fig. 2. Box regions for the identification of TC genesis.

Table 1. Specified areas designated for the different regions.

\begin{tabular}{lccc}
\hline $\begin{array}{l}\text { Longitude } \rightarrow \\
\text { Latitude } \downarrow\end{array}$ & $80-84.999 \mathrm{E}$ & $85-89.999 \mathrm{E}$ & $90-94.999 \mathrm{E}$ \\
\hline $15-19.999 \mathrm{~N}$ & B7 & B8 & B9 \\
$10-14.999 \mathrm{~N}$ & B4 & B5 & B6 \\
$5-9.999 \mathrm{~N}$ & B1 & B2 & B3 \\
\hline
\end{tabular}

Table 2. TC landfall occurrences in the five specified regions corresponding to selected periods.

\begin{tabular}{lrrrrrr}
\hline Period & R1 & R2 & R3 & R4 & R5 & Total \\
\hline $1901-2015$ & 32 & 51 & 38 & 63 & 8 & 192 \\
$1901-1950$ & 13 & 20 & 19 & 22 & 7 & 81 \\
$1961-2010$ & 15 & 26 & 15 & 37 & 1 & 94 \\
$1921-1950$ & 10 & 16 & 11 & 12 & 5 & 54 \\
$1961-1990$ & 9 & 20 & 10 & 28 & 0 & 67 \\
$1971-2000$ & 8 & 16 & 10 & 23 & 0 & 57 \\
$1981-2010$ & 7 & 12 & 9 & 18 & 1 & 47 \\
\hline
\end{tabular}

Between the two contrasting 50-yr periods, TCs had shown considerable increase of $68 \%$ over R4; $30 \%$ over R2, $15 \%$ over R1, whereas R5 had a maximum decrease of $86 \%$ followed by $21 \%$ over R3 in the later 50-yr period as compared to the first. The decline of TCs to 1 (15) in 1961-2010 from 7 (19) in 1901-1950 over R5 (R3) are to be viewed as significant. Considering $30-\mathrm{yr}$ totals, R4 alone has shown significant increase of $92-133 \%$ during the 30-yr periods of 1961-1990 and
1971-2000 as compared to 1921-1950 and there are no significant changes in R1, R2 and R3. Among the three 30-yr periods, TC landfall had a higher increase over the R4 region during 1961-1990 than the other two periods of 1971-2000 and 1981-2010. However, the TCs have reduced by $25 \%$ during the period 1981-2010 as compared to the two preceding 30 -yr periods. This indicates a general decrease of TC landfalls during recent years of global warming. This analysis also indicates an increased vulnerability of R4 (Bangladesh coast) with an increase of TC landfalls during the current global warming era. An investigation of the TC tracks that had landfall in R4 during the two 50-yr periods of 1901-1950 and 1961-2010 and the two 30-yr periods of 1921-1950 and 1981-2010 (figure 3) indicate that they originated over the eastern and southern parts of the BOB during the pre-global warming period, whereas their origin is localised to the southern parts of the BOB during the current global warming period. Thus, one of the reasons for the increase of TC landfall in the $\mathrm{R} 4$ region during the global warming period could be the shift in the genesis locations.

\subsection{Trends in TC genesis}

The numbers of genesis points in each of the nine designated box regions for the different periods are identified and given in table 3. During the total period of 1901-2015, 223 TC genesis locations have been identified of which maximum have occurred 


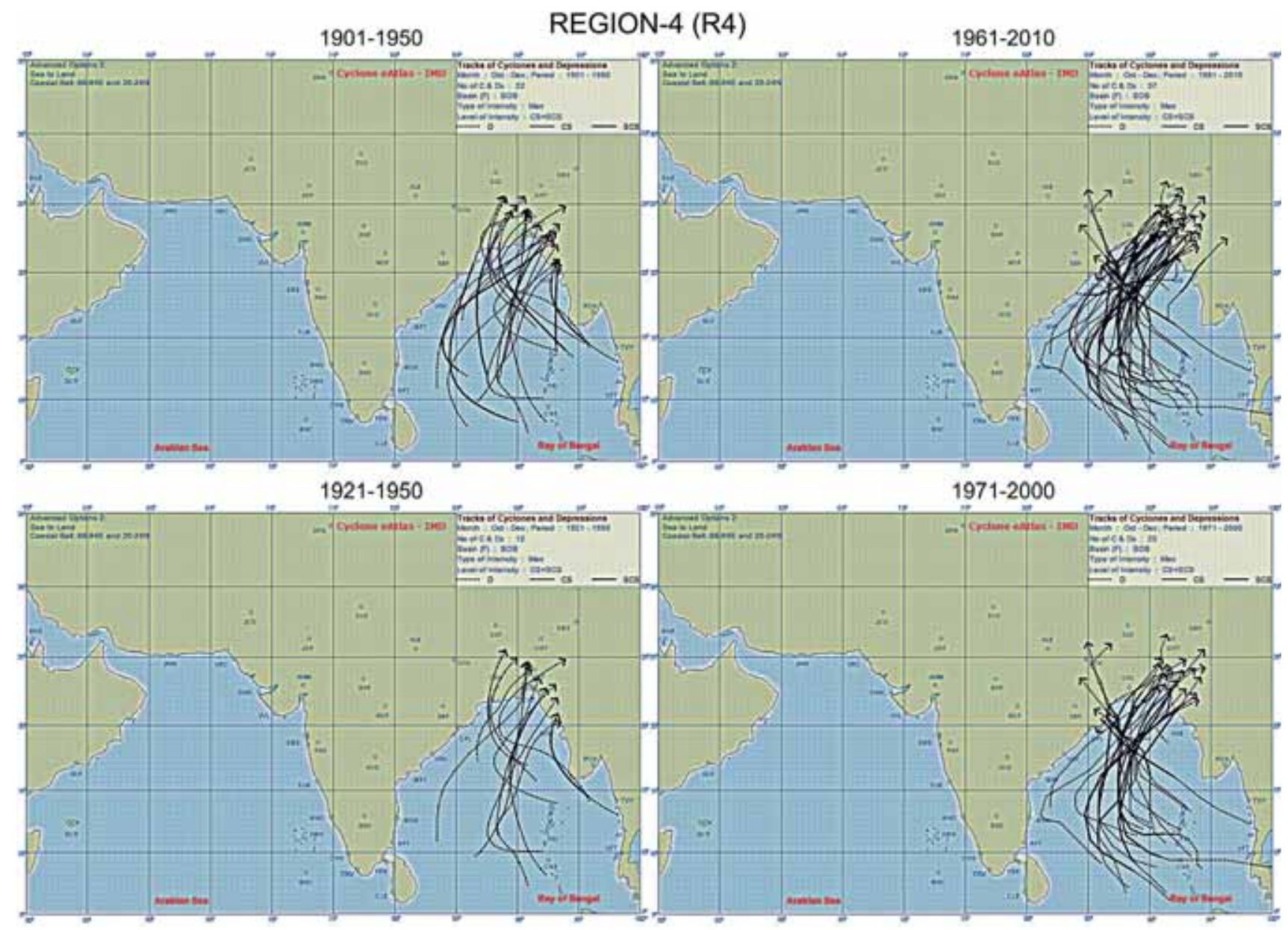

Fig. 3. TC tracks that had landfall in R4 during the two 50-yr periods (top panel) and the two 30-yr periods (bottom panel).

Table 3. Numbers of TC genesis in the nine specified regions over the BOB, during different time periods.

\begin{tabular}{|c|c|c|c|c|c|c|c|}
\hline Region & 1901-1950 & 1961-2010 & 1921-1950 & 1961-1990 & $1971-2000$ & 1981-2010 & 1901-2015 \\
\hline B1 & 12 & 5 & 6 & 4 & 3 & 2 & 20 \\
\hline B2 & 30 & 23 & 21 & 18 & 16 & 10 & 56 \\
\hline B3 & 11 & 22 & 11 & 16 & 11 & 7 & 38 \\
\hline B4 & 8 & 6 & 5 & 3 & 1 & 4 & 15 \\
\hline B5 & 15 & 20 & 5 & 15 & 13 & 10 & 38 \\
\hline B6 & 14 & 17 & 9 & 10 & 13 & 10 & 33 \\
\hline B7 & 1 & 2 & 0 & 2 & 1 & 0 & 4 \\
\hline B8 & 5 & 6 & 2 & 4 & 3 & 4 & 11 \\
\hline B9 & 3 & 3 & 3 & 2 & 2 & 3 & 8 \\
\hline Total & 99 & 104 & 62 & 74 & 63 & 50 & 223 \\
\hline
\end{tabular}

over B2 sequentially followed by B3, B5, B6, B1, B4, B8, B9 and B7. It may be noted here that this number (223) is more than the total number of landfall points (192) which is due to the dissipation of some of the TCs over the BOB itself and so are not accounted for as TCs with landfall. Herewith, the authors present the discussion referring to the box regions as with respect to the southern, central, northern, western and eastern regions of the BOB. The genesis locations are found to be the highest over the south BOB (B1, B2 and B3) considering meridional variation and over the central BOB (B2, B5 and B8) considering zonal variation indicating southern and central parts of the BOB to be more favourable for TC genesis. Considering the variations between two 50-yr periods of 1901-1950 and 
1961-2010, TC geneses are nearly the same during these two periods. However, considering the variations over the box regions which had at least 30 TCs during the total 115-yr study period, TC genesis significantly increased by about $100 \%$ in B3, $33 \%$ in B5 and 21\% in B6 while they decreased by $23 \%$ in B2.

Considering the $30-y r$ periods during the base and global warming era, similar trends as of 50-yr periods have been observed. Specifically, increasing trends are observed to be $\sim 100 \%$ in B5 and $10 \%$ in B6, whereas they decreased by $52 \%$ in B2. Considering the maximum genesis occurrences of 56 in $\mathrm{B} 2$ and 38 in B3 and B5 and 33 in B6 during 1901-2015, the significant increases over B5 (33\% in 50 -yr periods and about $100-200 \%$ in the three $30-y r$ periods as compared to 1921-1950) and B6 (21\% between the $50-\mathrm{yr}$ periods and $11-44 \%$ between the 30-yr periods) and decrease over B2 (23\% in 50-yr periods and $14-52 \%$ in the later three 30-yr periods than 1921-1950) clearly indicate a significant shift in the genesis locations from B2 to B5 and B6. The increasing tendency over B3 during the global warming era is noted to be consistent due to their increase $(100 \%)$ during the 50 -yr period of 1961-2010 and during the 30-yr periods of 1961-1990 and 1971-2000 although a decreasing tendency is observed during 1981-2010 which is due to the general decrease of TC genesis all over during the decade of 2001-2010. The increasing tendencies over central (B5) and east-central (B6) and south-east (B3) and decreasing tendencies over the south-central (B2) box regions indicate an eastward and northward shift of the genesis locations during the global warming era.

There is a notable decrease of total TC genesis from 74 in 1961-1990 to 50 in 1981-2010, and further analysis reveals that it is due to the decrease (13) of TC genesis during the recent decade of 2001-2010. This is also the reason for the decrease in the number of TC landfall since 1980s (table 2).

A review of the TC tracks originating from each of the designated nine box regions during the period 1901-2015 denote that (i) most of the tracks from B1 move towards the west or west/northwest; (ii) most from B2 move towards the west/ north-west and few towards the north and recurve towards the north-east; (iii) most and near equal percentage of TCs from B3 and B5 move towards the north-west and the north/north-east; (iv) most from B4 move towards the north; (v) most from B6 move towards the north-west or north/north-east; (vi) TCs from B8 move towards the west or north- west or north-east and (vii) TCs originating from B7 and B9 are small for assigning significant track directions. Analysis of tracks originating from the four regions which had maximum TC geneses (B2, B3, B5 and B6) show their movement as towards the north-west or north/north-east signifying that the southern and eastern parts of the BOB are important for TC genesis.

Further investigation of the TC tracks originating from the regions B3 and B5 during the two 50 -yr periods has been made to identify the impacts of increasing genesis from these two regions on the landfall locations (figure 4). The analysis reveals that an increase of $\mathrm{TC}$ genesis over B3 and B5 have contributed to the TC landfall increase over R4 while a part from B5 have contributed to the landfall over $\mathrm{R} 2$. This result means that TCs originating over the eastern parts of the BOB have a tendency for recurvature towards the north/north-east after the initial movement towards the north-west and TCs originating over the central BOB have a tendency of movement towards the west/north-west.

Analysis of the remnants of typhoons from the north-west Pacific contributing to the cyclogenesis over the BOB was investigated. Results show that these remnants from NW Pacific becoming TCs in the BOB during 1901-2015 were about 20. Considering the 30 -yr periods, the number was 8 during 1921-1950, and 5 during each of the $30-y r$ periods of 1961-1990, 1971-2000 and 1981-2010. This observation implies that a slightly higher number of TCs over the BOB was due to the remnants of the north-west Pacific typhoons during the prewarming period and the same reduced by $45 \%$ during the current warming period. This may signify that this could be one of the reasons for the observed decrease of cyclogenesis over the BOB during the 115-yr period.

\section{Climate change impacts on TC genesis and track}

In this section, the authors present plausible arguments for the observed trends in TC genesis and tracks due to climate change. Herein climate change means anthropogenic global warming due to the increase of greenhouse gases and for this reason, atmospheric and ocean variables affecting TCs only are considered for discussion. The favourable conditions for TC formation are large values of low-level vorticity, high SSTs, weak 

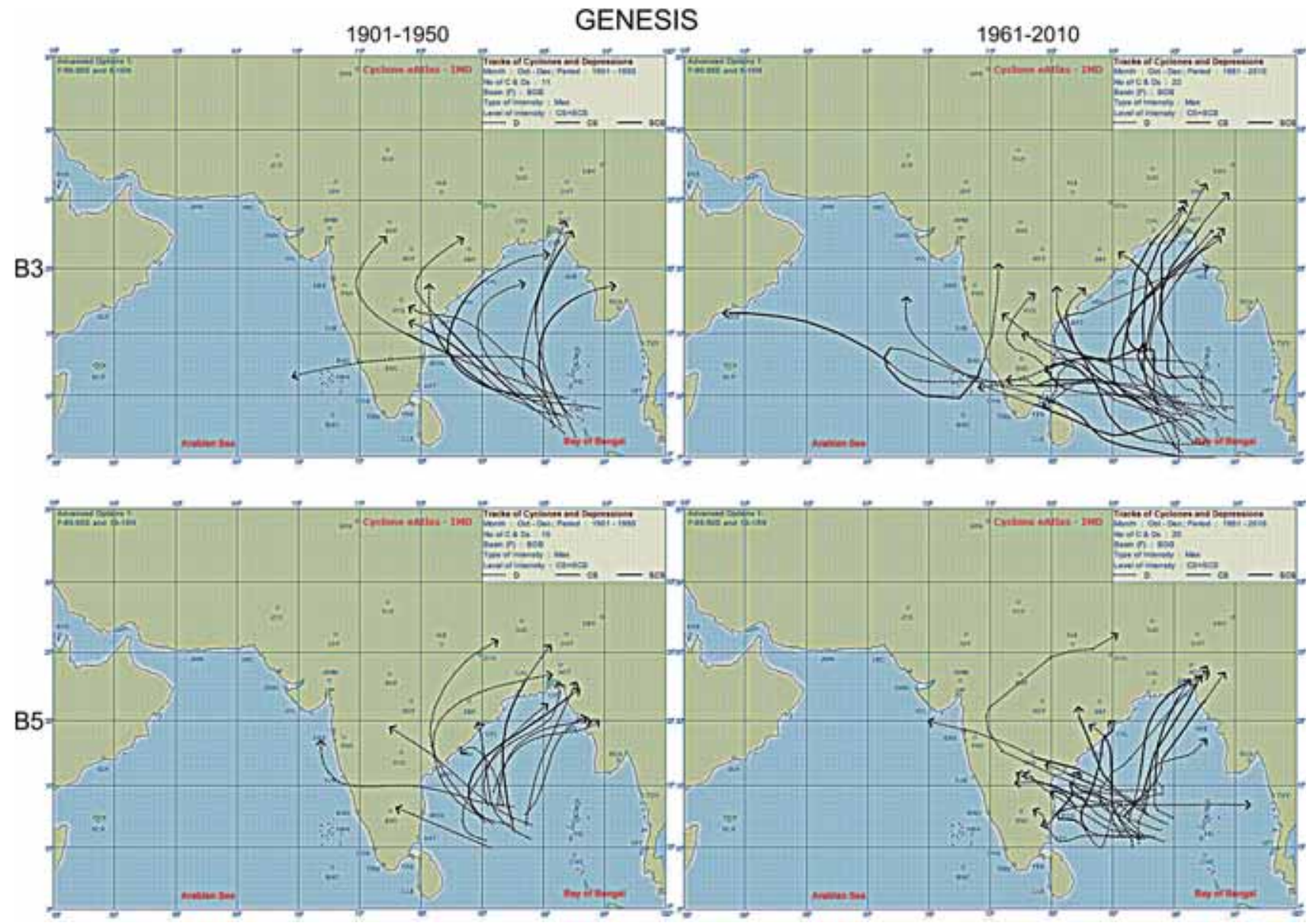

Fig. 4. TC tracks originating from the regions B3 (top panel) and B5 (bottom panel) for the periods 1901-1950 (left panel) and 1961-2010 (right panel).

vertical wind shear of the horizontal winds, and large values of relative humidity in the lower and middle troposphere (Gray 1968). Similarly, TC movement is influenced primarily by the steering current (atmospheric flow averaged between 850 and $200 \mathrm{hPa}$ levels) and secondarily due to the beta effect (latitudinal variation of the Coriolis parameter and wind speed) (Elsberry 1995). So the climate change impacts on TCs are to be interpreted from the observations or projections of these parameters.

The changes in TC genesis locations are to be attributed to the corresponding changes in the above referred genesis parameters (Gray 1968) and secondarily to other large-scale environmental forcing. A preliminary analysis of the four genesis parameters (vertical wind shear, low-level vorticity, lower troposphere humidity and SST) over the central BOB was made using ERA-20C (Poli et al. 2016) data for the period 1901-2010 and their time variations are shown in figure 5. The analysis reveals that SST and the lower troposphere humidity show a significant increasing trend, vertical wind shear shows an increasing trend significant at $50 \%$ level, while low-level vorticity has a significant decreasing trend. Of these four parameters, the magnitudes of mean low-level vorticity $\left(0.66 \times 10^{-5} \mathrm{~s}^{-1}\right)$ and vertical wind shear $\left(3 \times 10^{-3} \mathrm{~ms}^{-1} / \mathrm{hPa}\right)$ are less than their thresholds as necessary for cyclogenesis; whereas the mean magnitudes of relative humidity (79\%), and SST $\left(>28^{\circ} \mathrm{C}\right)$ are large enough for cyclogenesis and any significant increase in their magnitudes would favour the increase of cyclogenesis (Gray 1968).

Considering the importance of vertical wind shear as a dynamical parameter for cyclogenesis, its variations during the 110-yr period from 1901 to 2010 is analysed and interpreted. The long-term trends indicate a slight increase during this period, which corroborates with a slight decrease of TC genesis and this result is to be taken with the constraint that both the trends may not be statistically significant. Further analysis has shown that the increase in vertical wind shear is due to the 

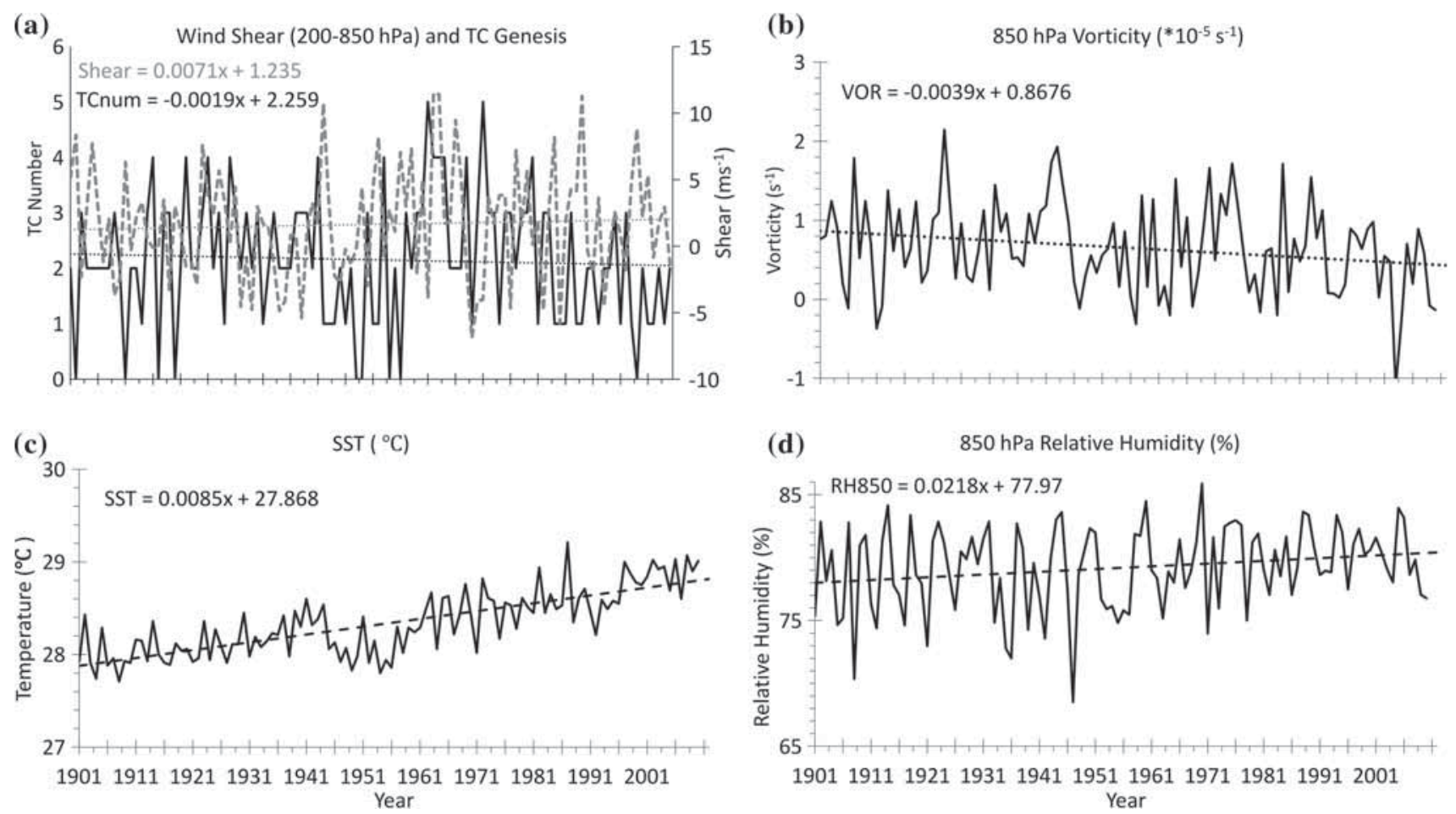

Fig. 5. Time series of the monthly mean of (a) vertical wind shear (u200-u850 hPa, m/s) along with the number of TCs per year; (b) low-level vorticity $\left(850 \mathrm{hPa}, \mathrm{s}^{-1}\right)$; (c) $\mathrm{SST}\left({ }^{\circ} \mathrm{C}\right)$ and $(\mathbf{d})$ lower-level humidity $(850 \mathrm{hPa}, \%)$ for November at $12.5 \mathrm{~N} ; 87.5 \mathrm{E}$.

reducing strength of the easterlies in the upper troposphere $(200 \mathrm{hPa})$ which is connected to the weakening of the subtropical high. Some of the earlier modelling studies have indicated the weakening of the Western part of the subtropical high or its shift eastward is due to global warming ( $\mathrm{Wu}$ and Wang 2004). The climate change impacts on $\mathrm{TC}$ tracks are to be interpreted in terms of changes in steering flow over the BOB region. TCs, south of 20-25N usually move towards the west with a slight northward component under the influence of the tropical easterlies equatorward of the east-west oriented subtropical ridge, and at times, when the subtropical ridge becomes weak due to a transient westerly trough, the TC may turn poleward and may recurve toward the east under the influence of the westerlies poleward of the subtropical ridge (Elsberry 1995). Since the present analysis shows that more TCs had moved towards the north and the north-east with an increase of landfall locations on the Bangladesh coast, a weakening of the subtropical high may be the reason for more TCs to have recurvature leading to landfall over the Bangladesh coast. A weakening of the subtropical high seems to explain both the shift of the TC genesis locations towards the east and the north and the increasing northward TC movement.
The northward movement of the SIDR (2007) cyclone with its landfall over the Bangladesh coast and the north/north-east/east movement of the NARGIS (2008) cyclone with its landfall over the Myanmar coast under the influence of the transient upper tropospheric trough (India Meteorological Department 2008, 2009) support this hypothesis. Considering the steering flow, the beta effect may also supplement as higher intensity TCs in the global warming scenario may have higher translating speed and have significant effect on changing the direction of motion towards the north and the north-east. Modelling studies over Australia have indicated the poleward shift of TC genesis and their tendency towards poleward movement (Walsh and Jack 2000) support this hypothesis. This explanation needs further analysis for validation.

\section{Summary}

Historical TC data over the BOB covering the 3 -month period from October to December during 1901-2015 were analysed to investigate the trends in TC genesis and landfall locations in association with the current global warming and climate 
change. The climate change impacts due to global warming are reflected as

- increase of TC landfall, maximum over the Bangladesh coast and moderate over Tamil Nadu and South Andhra coasts of India;

- decrease of TC landfall, maximum over the Myanmar coast and moderate over the Orissa coast (India);

- increase of TC genesis over the south-east and central BOB; decrease over the south-central regions of the $\mathrm{BOB}$;

- increase of landfall over Bangladesh coast is due to the increase of TC genesis over the south-east BOB;

- increase of landfall over Tamil Nadu coast is due to the increase of TC genesis over the central BOB.

Considering the total number of TCs (CS+SCS) that have originated during 1921-1950 (base period) and 1981-2010, it is observed that this number decreased by $22 \%$ whereas the number of SCS has increased by $25 \%$. This signifies that although the total number of TC systems is decreasing, the intensity of TCs had increased in the global warming era.

A comparison of $\mathrm{TC}$ genesis and landfall numbers denotes that about 31 TCs had dissipated over the ocean during the total period of 1901-2015, of which the dissipations were 18 during 1901-1950 as compared to 10 during 1961-2010. This signifies that global warming has contributed to stronger TCs during the recent 50-yr period.

The present study brings out, importantly and uniquely, the shift of the TC genesis locations towards the east and increased the vulnerability of the Bangladesh coast in the era of global warming and climate change. The shift in TC genesis location and the TC movement towards the north are attributed to the increase in vertical wind shear and increased westerly trough activity, respectively, both resulting from a weakening of the subtropical high due to global warming and climate change. In addition, TC systems are found to decrease but with increased intensities over the $\mathrm{BOB}$ in the global warming era. The identification of a higher number of TC genesis locations to the south and east imply that the genesis locations are farther from the landfall over the Indian subcontinent, which denote more intense cyclone systems to have landfall along the Indian east coast.

\section{Acknowledgements}

Tropical cyclone track data for the north Indian Ocean in the form of eAtlas from the India Meteorological Department were accessed. The open access SST data from National Oceanic and Atmospheric Administration and atmospheric data from ERA-20C from the European Centre for Medium-Range Weather Forecast have been used.

\section{References}

Bhaskar Rao D V, Naidu C V and SrinivasaRao B 2001 Trends and fluctuations of the cyclonic systems over North Indian Ocean; Mausam 52 1-8.

Brohan P, Kennedy J J, Haris S F B, Tett I and Jones P D 2006 Uncertainty estimates in regional and global observed temperature changes: A new dataset from 1850; J. Geophys. Res. 111 D12106.

Christensen J H, Krishna Kumar K, Aldrian E, An S-I, Cavalcanti I F A, de Castro M, Dong W, Goswami P, Hall A, Kanyanga J K, Kitoh A, Kossin J, Lau N-C, Renwick J, Stephenson D B, Xie S-P and Zhou T 2013 Climate phenomena and their relevance for future regional climate change; In: Climate change 2013: The physical science basis. Contribution of working group I to the fifth assessment report of the intergovernmental panel on climate change (eds) Stocker T F, Qin D, Plattner G-K, Tignor M, Allen S K, Boschung J, Nauels A, Xia Y, Bex V and Midgley P M, Cambridge University Press, Cambridge, UK and New York, NY, USA, pp. 1217-1308.

Diaz H F and Pulwarty R S (eds) 1997 Hurricanes: Climate and socioeconomic impacts; Springer-Verlag, p. 292.

Elsberry R L 1995 Recent advancements in dynamical tropical cyclone track predictions; Meteorol. Atmos. Phys. 56 81-99.

Gray W M 1968 Global view of the origin of tropical disturbances and storms; Mon. Weather Rev. 96 669-700.

India Meteorological Department 2008 Report on Cyclonic Disturbances over North Indian Ocean during 2007; India Meteorological Department, New Delhi, India.

India Meteorological Department 2009 Report on Cyclonic Disturbances over North Indian Ocean during 2008; India Meteorological Department, New Delhi, India.

IPCC 2007 Summary for policymakers; In: Climate change 200\%: The physical science basis. Contribution of working group I to the fourth assessment report of the intergovernmental panel on climate change (eds) Solomon S, Qin D, Manning M, Chen Z, Marquis M, Averyt K B, Tignor M and Miller H L, Cambridge University Press, Cambridge, UK and New York, NY, USA, pp. 1-996.

IPCC 2013 Summary for policymakers; In: Climate change 2013: The physical science basis. Contribution of working group I to the fifth assessment report of the intergovernmental panel on climate change (eds) Stocker T F, Qin D, Plattner G K, Tignor M, Allen S K, Boschung J, Nauels A, Xia Y, Bex $\mathrm{V}$ and Midgley $\mathrm{P}$ M, Cambridge University Press, Cambridge, UK and New York, NY, USA, p. 28. 
Poli P, Hersbach H, Dee D P, Berrisford P, Simmons A J, Vitart F, Laloyaux P, Tan D G, Peubey C, Thépaut J, Trémolet Y, Hólm E V, Bonavita M, Isaksen L and Fisher M 2016 ERA-20C: An atmospheric reanalysis of the twentieth century; J. Clim. 29 4083-4097.

Rahmstorf S, Foster G and Cahill N 2017 Global temperature evolution: Recent trends and some pitfalls; Env. Res. Lett. 12054001.

Sellers H A, Zhang H, Berz G, Emanuel K, Gray W, Landsea C, Holland G, Lighthill J, Shieh S-L, Webster P and McGuffie K 1998 Tropical cyclones and global climate change: A post-IPCC assessment; Bull. Am. Meteor. Soc. 79 19-38.

Corresponding editor: Kavirajan RAJENDRAN
Smith T M and Reynolds R W 2003 Extended reconstruction of global sea surface temperature based on COADS data (1854-1997); J. Clim. 16 1495-1510.

Smith T M, Reynolds R W, Peterson T C and Lawrimore J 2008 Improvements to NOAA's historical merged landocean surface temperature analysis (1880-2006); J. Clim. $212283-2296$.

Walsh K J E and Jack J K 2000 The impact of climate change on the poleward movement of tropical cyclone-like vortices in a regional climate model; J. Clim. 13 1116-1132.

Wu L and Wang B 2004 Assessing impacts of global warming on tropical cyclone tracks; J. Clim. 17 1686-1698. 